\title{
Spectrophotometric Determination of Silicate in Water with Molybdate and Malachite Green
}

\author{
Shoji Moтomizu, Mitsuko Oshima and Yuka OJIma \\ Department of Chemistry, Faculty of Science, Okayama University, Tsushimanaka, Okayama 700, Japan
}

\begin{abstract}
On the basis of the coloration formed with molybdosilicate and Malachite Green in aqueous solution, trace amounts of silicate were determined. In an acidic medium, silicate reacted with molybdate to form molybdosilicate, which reacted with Malachite Green to form a colored ion association complex. The color was stabilized by adding poly(vinyl alcohol). The molar absorptivity was $1.0 \times 10^{5} 1 \mathrm{~mol}^{-1} \mathrm{~cm}^{-1}$ at $595 \mathrm{~nm}$, and the absorbance of the reagent blank was 0.089 . The recommended concentration range of silicon was $0.1-5 \mu \mathrm{g}$ and the limit of detection was $0.01 \mu \mathrm{g}$ of silicon. Silicate in river and tap waters was determined.
\end{abstract}

Keywords Spectrophotometry, silicate determination, molybdate, Malachite Green, ion association complex

The determination of silicon is becoming more and more important in such fields as semiconductors, metallurgical products, industrial and purified waters and biomedical samples. Spectrophotometric methods of silicon commonly involve a procedure of conversion of various forms of silicon into soluble silicate as a preliminary step. Most of the spectrophotometric methods are based on the formation of heteropolyacids, molybdosilicate, in an acidic medium. The heteropolyacid of silicate formed has been used as a light-absorbing species either as it is, after reduction to a heteropoly blue species or after extraction into an organic solvent as a protonated species. The molar absorptivities of each heteropolyacid by itself are generally not so large. One of the highly sensitive spectrophotometric methods of heteropolyacid-forming analyte is based on the ion association reaction between a heteropolyacid and a cationic dye. Several cationic dyes: Butylrhodamine $\mathbf{B}^{1}$, Rhodamine B ${ }^{2,3,5}$, Crystal Violet ${ }^{4,6}$, Malachite Green ${ }^{4,7}$, and Methyl Green ${ }^{8,9}$ have been examined for the spectrophotometric determination of silicate. These cationic dyes have been used in the color development in an aqueous solution ${ }^{1-3,5,6}$, in the flotation ${ }^{3-5}$ or the precipitation ${ }^{7,8}$ of an ion association complex, followed by solution of them in an organic solvent and in the solvent extraction ${ }^{2}$. The methods using the flotation of the ion association complex are sensitive, but the procedures are troublesome. The methods using the color development of ion associate in an aqueous solution are very simple, but the blank absorbances are generally large. In our previous papers of phosphate determination ${ }^{10-12}$, Malachite Green was selected because of the stability of coloration in an acidic medium.

In this work, the authors examined the spectro- photometric method for determination of silicate in an acidic medium with molybdate and Malachite Green. The proposed method is simple and sensitive, and the blank absorbance is small.

\section{Experimental}

Apparatus

Absorption measurements were made on a Hitachi 139 spectrophotometer and a Shimadzu UV-300 recording spectrophotometer in a $10-\mathrm{mm}$ glass cell.

\section{Reagents}

The standard silicate solution was prepared as follows. Transfer $10 \mathrm{ml}$ of a commercially available silicate standard solution for AAS (1000 ppm) into a polytetrafluoroethylene (PTFE) beaker and add $1.2 \mathrm{ml}$ of $2 \mathrm{M}$ potassium hydroxide solution. Heat the solution for $10 \mathrm{~min}$ on a hot plate adjusted to $175^{\circ} \mathrm{C}$. Then transfer it into a $25-\mathrm{ml}$ of polypropylene measuring flask and dilute to the mark with water. Working solutions were prepared by diluting it accurately.

A molybdate solution ( $0.2 \mathrm{M}$ as molybdenum) was prepared using ammonium heptamolybdate tetrahydrate (E. Merck).

Commercially available Malachite Green (MG) (oxalate) (Wako Pure Chemical Ind. Ltd.) was dissolved in distilled water to give $4 \times 10^{-3} \mathrm{M}$ solution $(0.1854 \mathrm{~g} / 100 \mathrm{ml})$.

Polyvinylalcohol (PVA) solution was prepared by dissolving $5 \mathrm{~g}$ of commercially available PVA (average degree of polymerization, 500 ) in $100 \mathrm{ml}$ of distilled water.

Super special grade of sulfuric acid (Wako Pure 
Chemical Ind. Ltd.) was used.

PTFE, polypropylene or polyethylene vessels were used throughout.

\section{Standard procedure for determination}

To a $25-\mathrm{ml}$ polypropylene measuring flask, transfer $20 \mathrm{ml}$ of sample solution. Add $1 \mathrm{ml}$ of $3.75 \mathrm{M}$ sulfuric acid and $1.5 \mathrm{ml}$ of $0.2 \mathrm{M}$ (as molybdenum) molybdate solution to it, and mix thoroughly. After heating it in a boiling water bath for $10 \mathrm{~min}$, cool to room temperature with water. Add $0.5 \mathrm{ml}$ of $5 \%$ PVA solution and $0.5 \mathrm{ml}$ of $4 \times 10^{-3} \mathrm{M}$ MG solution. Dilute to the mark with water and stand for $60 \mathrm{~min}$ after mixing. Measure the absorbance at $595 \mathrm{~nm}$.

\section{Results and Discussion}

\section{Effect of acidity}

The effect of acidity on the reaction was examined using sulfuric acid. In Fig. 1, the effect of sulfuric acid concentration was shown. Constant and highest absorbances were obtained at the range from $0.14 \mathrm{M}$ to $0.15 \mathrm{M}$. At lower concentration of sulfuric acid the blank absorbance was very large because of the coloration of MG, and at higher concentration range the formation of molybdosilicate was less, though the blank absorbance was small because of a transformation into a protonated yellow form of MG. In this work, $0.15 \mathrm{M}$ sulfuric acid in $25 \mathrm{ml}$ of final solution was adopted.

\section{Effect of molybdate concentration}

The effect of molybdate concentration was examined. The results are shown in Fig. 2. Constant and highest

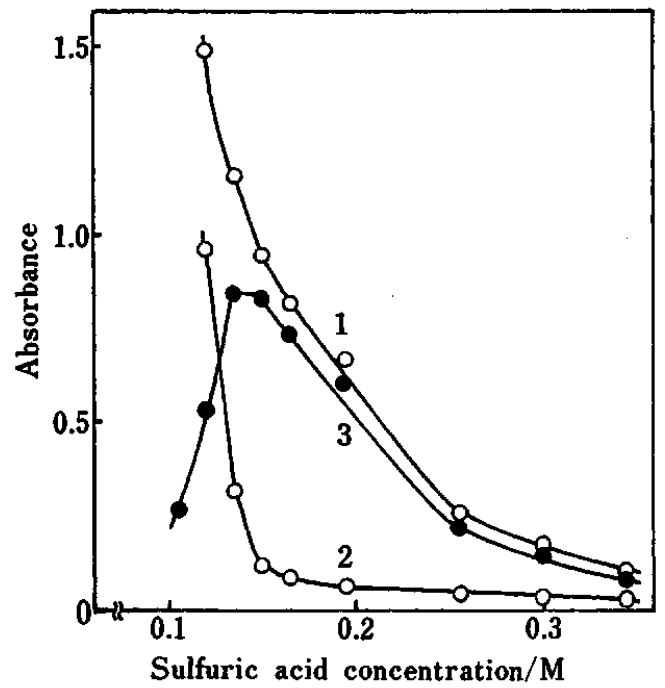

Fig. 1 Effect of sulfuric acid concentration. 1, silicate $6 \times$ $10^{-6} \mathrm{M} ; 2$, reagent blank; 3, net absorbance. Surfuric acid, $0.15 \mathrm{M}$; molybdate, $1.2 \times 10^{-2} \mathrm{M}$ (as molybdenum); $\mathrm{MG}$, $8 \times 10^{-5} \mathrm{M}$; PVA, $0.1 \%$. absorbances were obtained over the concentration of $1.2 \times 10^{-2} \mathrm{M}$ as molybdenum. In this work, $1.2 \times 10^{-2} \mathrm{M}$ molybdenum(VI) was adopted, that is, $1.5 \mathrm{ml}$ of $0.2 \mathrm{M}$ (as molybdenum) molybdate solution was added into $25 \mathrm{ml}$.

\section{Effect of Malachite Green concentration}

The effect of the MG concentration is shown in Fig. 3. The color development for both silicate and the blank absorbance increased gradually with increases in the MG concentration. At concentrations near $1.8 \times 10^{-4}$ M of MG, net absorbance for silicate was almost maximum, though the blank absorbance was very large. As a compromise, considering the blank absorbance

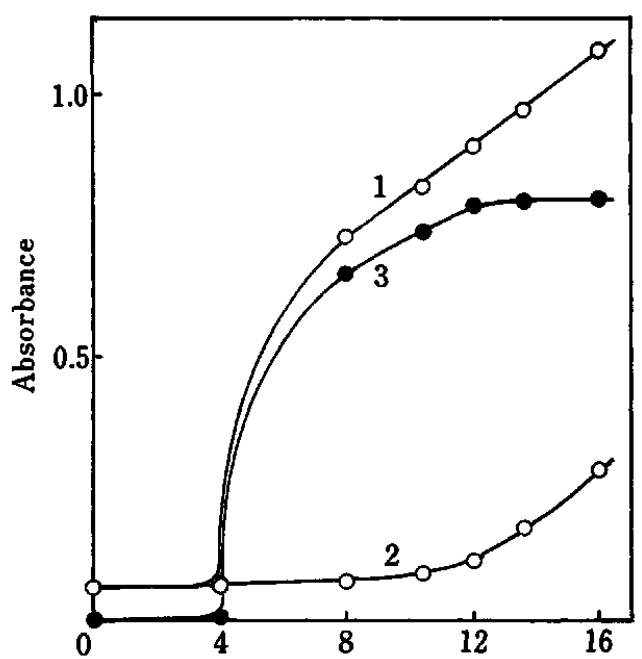

Molybdate as molybdenum concentration $/ 10^{-3} \mathrm{M}$

Fig. 2 Effect of molybdate concentration. 1, silicate $6 \mathrm{X}$ $10^{-6} \mathrm{M} ; 2$, reagent blank; 3 , net absorbance.

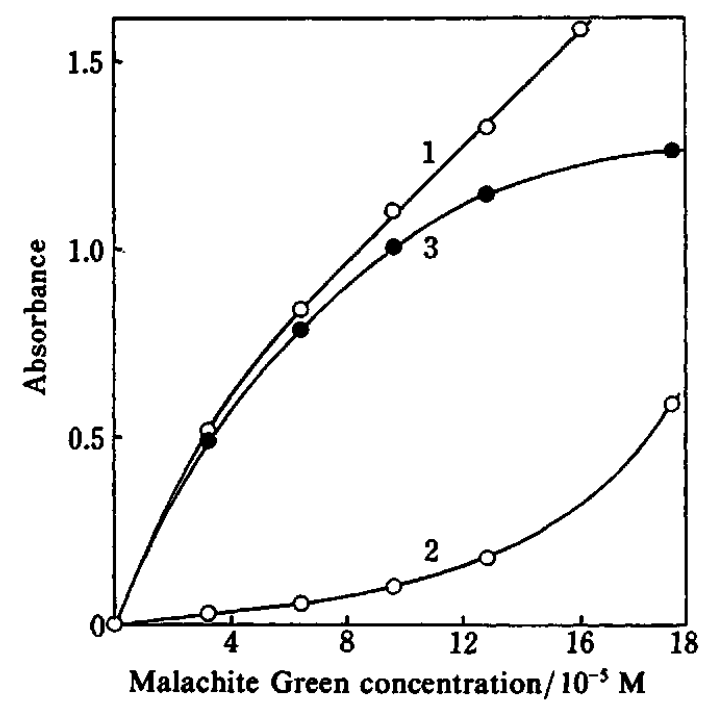

Fig. 3 Effect of Malachite Green concentration. 1, silicate $6 \times 10^{-6} \mathrm{M} ; 2$, reagent blank; 3, net absorbance. 
and sensitivity, MG concentration was fixed at $8 \times 10^{-5} \mathrm{M}$.

\section{Heating time}

Effects of heating time for accelerating the formation of molybdosilicate and the ion associate between molybdosilicate and Malachite Green are shown in Fig. 4. At first, an unstable $\beta$ type of molybdosilicate was formed. Then, it changed to stable $\alpha$ type of molybdosilicate within $9 \mathrm{~min}$. Ion associate was formed between $\alpha$ type molybdosilicate and MG, so that the heating time was fixed at $10 \mathrm{~min}$.

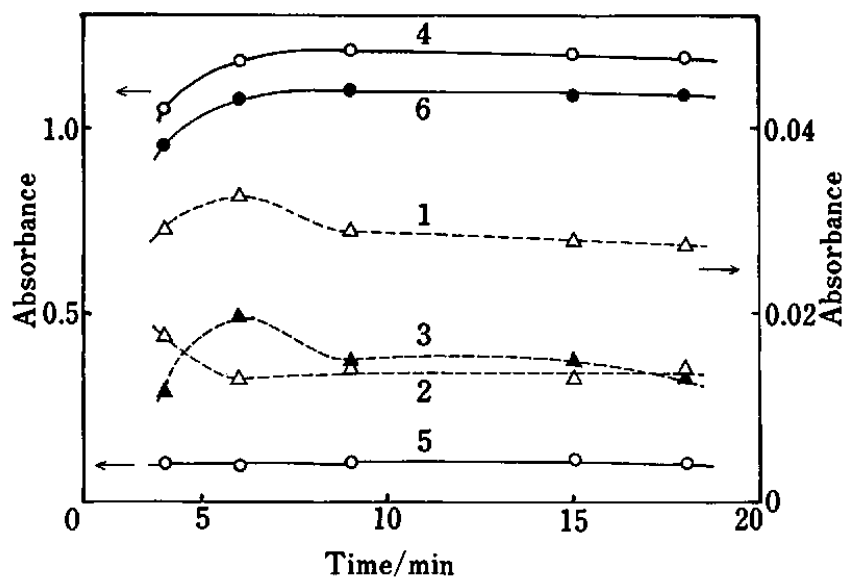

Fig. 4 Effect of heating time on the formation of molybdosilicate and the formation of an ion associate between molybdosilicate and Malachite Green. 1,2 and 3 for the formation of molybdosilicate on the right scale, and 4, 5 and 6 for the formation of ion assoiate on the left scale. 1 and 4 , silicate $8 \times 10^{-6} \mathrm{M} ; 2$ and 5 , reagent blank; 3 and 6 , net absorbance.

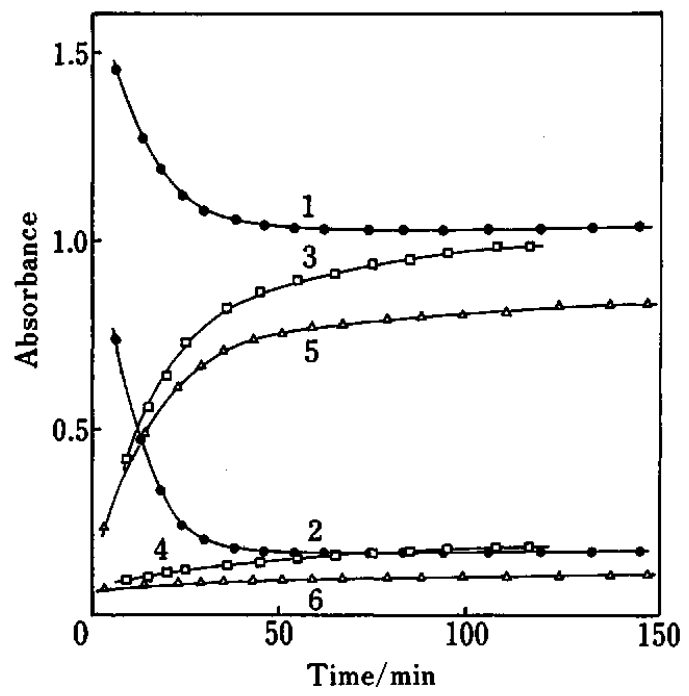

Fig. 5 Effect of standing time on color development of Malachite Green. Sulfuric acid concentration added to Malachite Green solution; 1 and 2, $0 \mathrm{M}$ (pH 3); 3 and 4, 0.02 $\mathrm{M}$ (pH 1.6); 5 and 6, $0.15 \mathrm{M}$ (pH 0.8). 1, 3 and 5, silicate $6 \times 10^{-6} \mathrm{M} ; 2,4$ and 6 , reagent blank.

\section{Standing time}

The time for the color development of MG was examined using an MG solution acidified before use and one not acidified. The results are shown in Fig. 5. In the case of the MG solution without acidifying, the time for color development of MG was the shortest and the absorbances were the highest. The measurement of the absorbance was carried out more than $\mathbf{5 0}$ min after the addition of MG solution.

\section{Calibration graph}

Calibration graph was rectilinear at the range from $10^{-7} \mathrm{M}$ (Si $2.81 \mu \mathrm{g} \mathrm{l}^{-1}$ ) to $10^{-5} \mathrm{M}$ (Si $280.86 \mu \mathrm{g} \mathrm{l}^{-1}$ ) of silicate and the molar absorptivity was $1.0 \times 10^{5} 1 \mathrm{~mol}^{-1}$ $\mathrm{cm}^{-1}$ at maximum wavelength, $595 \mathrm{~nm}$. The mean absorbances of 10 measurements of $6 \times 10^{-6} \mathrm{M}(\mathrm{Si}$ $168.51 \mu \mathrm{g}^{-1}$ ) of silicate and blank were 0.939 and 0.089 , respectively, and the relative standard deviation were $1.5 \%$ and $5.0 \%$, respectively.

\section{Effect of diverse ions}

In Table 1, the effects of diverse ions are listed. Most

Table 1 Effects of diverse ions

\begin{tabular}{|c|c|c|}
\hline Ions & Added as & Tolerable concn. $\mathrm{a} / \mathrm{M}$ \\
\hline $\mathrm{K}^{+}, \mathrm{Cl}^{-}$ & $\mathrm{KCl}$ & $1 \times 10^{-2}$ \\
\hline $\mathrm{Na}^{+}, \mathrm{NO}_{3}^{-}$ & $\mathrm{NaNO}_{3}$ & $1 \times 10^{-2}$ \\
\hline $\mathrm{HCO}_{3}^{-}$ & $\mathrm{NaHCO}_{3}$ & $5 \times 10^{-3}$ \\
\hline $\mathrm{Ca}^{2+}$ & $\mathrm{CaCl}_{2}$ & $5 \times 10^{-3}$ \\
\hline $\mathrm{NH}_{4}^{+}$ & $\mathrm{NH}_{4} \mathrm{Cl}$ & $5 \times 10^{-3}$ \\
\hline $\mathrm{Mg}^{2+}, \mathrm{SO}_{4}{ }^{2-}$ & $\mathrm{MgSO}_{4}$ & $5 \times 10^{-3}$ \\
\hline $\mathrm{Co}^{2+}$ & $\mathrm{CoSO}_{4}$ & $1 \times 10^{-3}$ \\
\hline $\mathrm{Cu}^{2+}$ & $\mathrm{CuSO}_{4}$ & $1 \times 10^{-3}$ \\
\hline $\mathrm{Ni}^{2+}$ & $\mathrm{NiSO}_{4}$ & $1 \times 10^{-3}$ \\
\hline $\mathrm{Zn}^{2+}$ & $\mathrm{ZnSO}_{4}$ & $5 \times 10^{-4}$ \\
\hline $\mathrm{Al}^{3+}$ & $\mathrm{Al}_{2}\left(\mathrm{SO}_{4}\right)_{3}$ & $1 \times 10^{-4}$ \\
\hline $\mathrm{Fe}^{3+}$ & $\mathrm{FeNH}{ }_{4}\left(\mathrm{SO}_{4}\right)_{2}$ & $1 \times 10^{-4}$ \\
\hline $\mathbf{F}^{-}$ & $\mathrm{NaF}$ & $1 \times 10^{-5}$ \\
\hline $\mathrm{W}(\mathrm{VI})$ & $\mathrm{Na}_{2} \mathrm{WO}_{4}$ & $5 \times 10^{-6}$ \\
\hline $\mathrm{PO}_{4}{ }^{3-}$ & $\mathrm{KH}_{2} \mathrm{PO}_{4}$ & $2 \times 10^{-7}$ \\
\hline $\operatorname{As}(V)$ & $\mathrm{Na}_{2} \mathrm{HAsO}_{4}$ & $2 \times 10^{-7}$ \\
\hline
\end{tabular}

a. Concentrations within \pm 0.02 absorbances for the absorbance of $6 \times 10^{-6} \mathrm{M}$ silicate solution.

Table 2 Analytical results for orthosilicate in waters

\begin{tabular}{rlc}
\hline Sample $^{\mathrm{a}}$ & Silicate as Si,ppm \\
\hline Zasu River & A & 5.9 \\
& B & 5.6 \\
& C & 5.6 \\
& D & 6.5 \\
Tap water & A & \\
& B & 5.3 \\
\hline
\end{tabular}

a. These were sampled on different dates, and $2 \mathrm{ml}$ of these were taken for the determination. 
of them do not interfere with the determination of silicate, but phosphate and arsenate ions interfere severely. Under the same conditions as that of silicate, phosphate and arsenate ions react quantitatively. Their molar absorptivities were $1.04 \times 10^{5}$ and $1.03 \times 10^{5} \mathrm{I} \mathrm{mol}^{-1}$ $\mathrm{cm}^{-1}$ at $595 \mathrm{~nm}$, respectively. In the determination of silicate in practical samples such as river water, there is no problem because of low concentration of phosphate and arsenate ions.

\section{Determination of silicate in waters}

In river water, silicate exists in various forms: monomeric, polymeric, soluble, insoluble and colloidal forms. Of these, soluble monomeric silicic acid (orthosilicic acid) and its silicate form molybdosilicic acid. Thus, without pretreatment, only orthosilicate can be determined. Analytical results in river and tap waters are shown in Table 2.

\section{References}

1. G. Xi and N. Zhang, Fen. Hsi Hua Hsuch, 9, 6 (1981); Anal. Abstr., 41, 3B121 (1981).
2. A. Golkowska, Chimia Analit., 14, 803 (1969).

3. A. Golkowska, Chimia Analit., 15, 591 (1970).

4. A. K. Babko and E. M. Ivashkovich, Zh. Anal. Khim., 27, 120 (1972).

5. A. Golkowska and L. Pszonicki, Talanta, 20, 749 (1973).

6. Z. Wang and Y. Zheng, Fenxi Huaxue, 14, 15 (1986); Anal. Abstr., 48, 9B109 (1986).

7. F. V. Mirzoyan, V. M. Tarayan and Z. A. Karapetyan, Arm. Khim. Zh., 34, 122 (1981); Anal. Abstr., 41, 3B120 (1981).

8. V. M. Tarayan, F. V. Mirzoyan and Z. A. Karapetyan, Dokl. Akad. Nauk Arm. SSR, 63, 168 (1976); Anal. Abstr., 33, 5B123 (1977).

9. F. V. Mirzoyan, V. M. Tarayan and Z. A. Karapetyan, Zavod. Lab., 44, 1184 (1978).

10. S. Motomizu, T.Wakimoto and K. Tôei, Talanta, 31, 235 (1984).

11. S. Motomizu, T. Wakimoto and K. Tôei, Analyst [London], 108, 361 (1983).

12. S. Motomizu, T. Wakimoto and K. Tôei, Talanta, 30, 333 (1983).

(Received September 22, 1988)

(Accepted November 4, 1988) 